\title{
FABRICAÇÃO DE PAVIMENTOS INTERTRAVADOS (PAVERS) UTILIZANDO RESÍDUOS DE BORRACHA DE PNEUS INSERVÍVEIS E RESÍDUOS DA CONSTRUÇÃO CIVIL (RCC) COMO AGREGADO MIÚDO
}

\author{
Ana Paula da Silva ${ }^{1}$ \\ Vitória Mendes Calderaro² \\ Gustavo da Silva $\mathrm{Cruz}^{3}$ \\ Erika Peterson Gonçalves ${ }^{4}$
}

Resumo: Atualmente muito se estuda sobre a destinação de resíduos, principalmente da construção civil (RCC) e de pneus inservíveis após a reciclagem. Este trabalho estuda a utilização de resíduos inservíveis de pneu e de construção civil na fabricação de pavimentos Intertravados (pavers) como substituição de agregados miúdos, como a areia, sem a redução na resistência a compressão, tração e resistência na análise da estrutura do pavimento. Neste estudo, avaliou-se o comportamento em compressão dos pavers produzidos com adição de resíduo de construção e borracha inservível, porém muito há de ser avaliado, quanto ao comportamento em tração, módulo de elasticidade, resistência à abrasão e ao impacto e por fim resistência à intempéries, visto que a substituição de cimento na formulação pela adição de borracha pode causar variações que ainda não podem ser estimadas, visto a falta de literatura na área.

Palavras-chave: Resíduos; Reciclagem; Pneus; Pavimentos Inter travados; Construção civil.

\footnotetext{
${ }^{1}$ Faculdade de Engenharia, Arquitetura e Urbanismo - FEAU/ Universidade do Vale do Paraíba - UNIVAP, Brasil. E-mail: analuap2000@yahoo.com.br.

2 Faculdade de Engenharia, Arquitetura e Urbanismo - FEAU/ Universidade do Vale do Paraíba - UNIVAP, Brasil. E-mail: vickcalderaro@hotmail.com.

${ }^{3}$ Faculdade de Engenharia, Arquitetura e Urbanismo - FEAU/ Universidade do Vale do Paraíba - UNIVAP, Brasil. E-mail: gustavocruz100@gmail.com.

${ }^{4}$ Faculdade de Engenharia, Arquitetura e Urbanismo - FEAU/ Universidade do Vale do Paraíba - UNIVAP, Brasil. E-mail: erika@univap.br.
} 